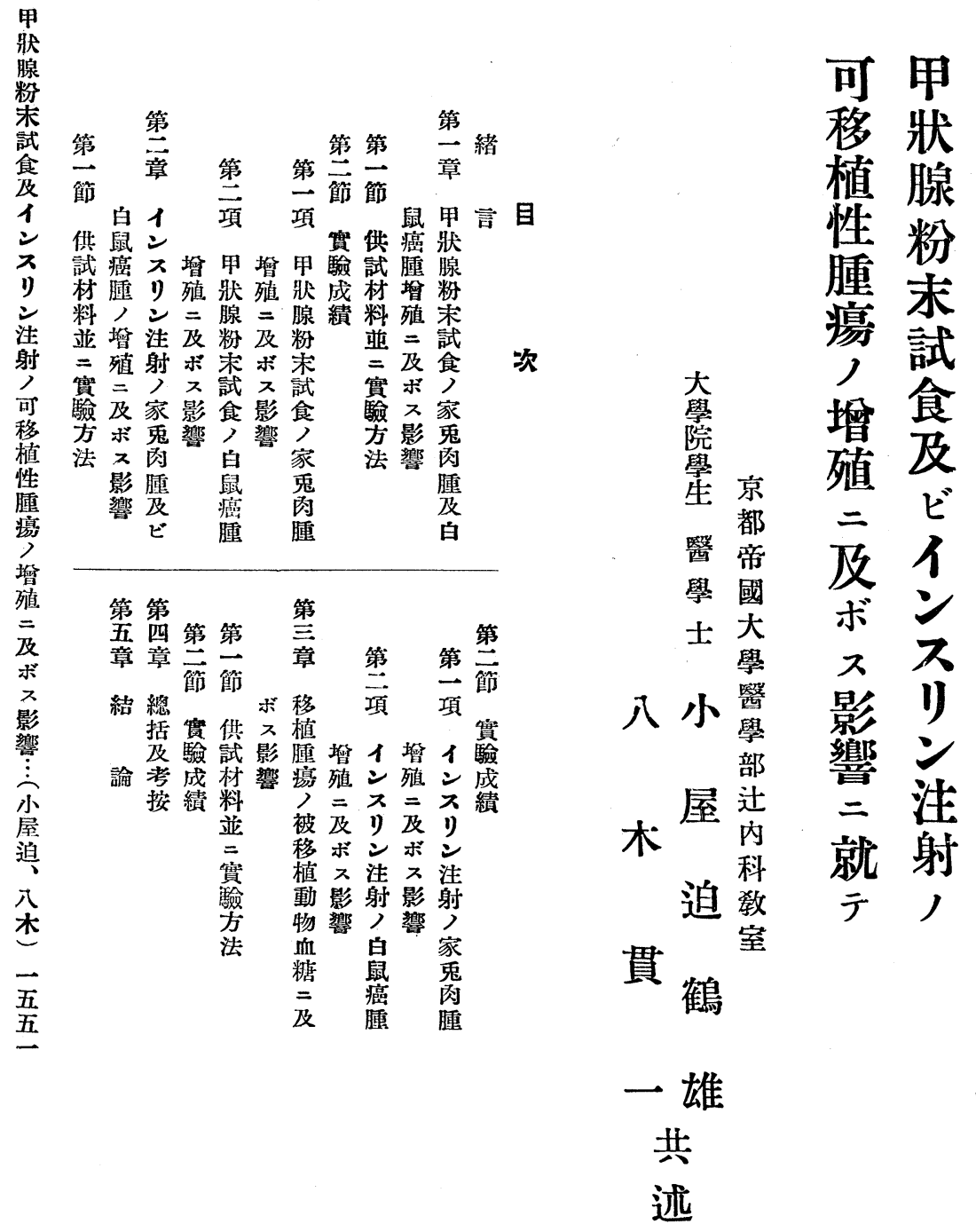




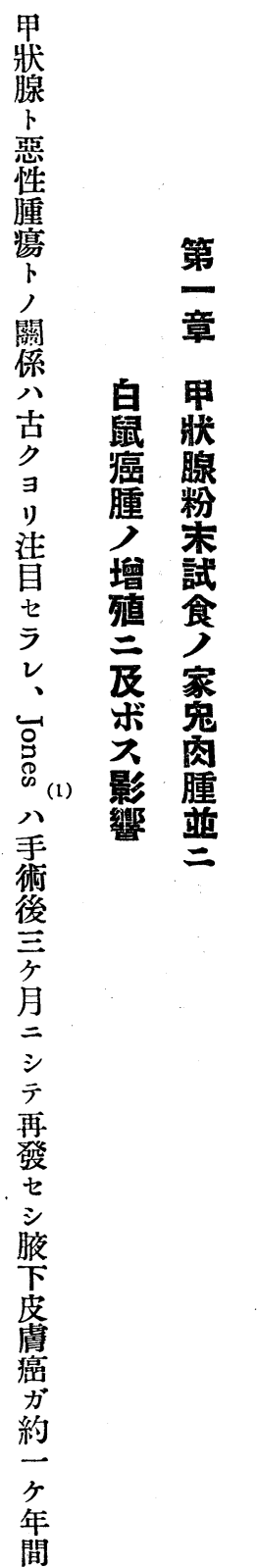

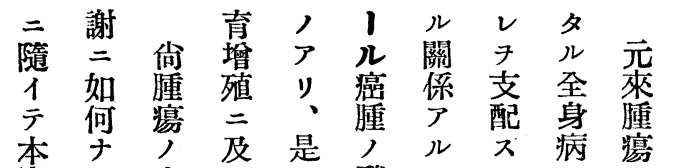

實ル本ボニ發コルノナ

驗障態 中害 影亏垍 八約症モ 子究瞳 余殖想ナ候, 肉菍么 走 動 ス 重究此走 $\begin{array}{lllllll}\text { 物 } & \text { 重 } & \text { ノ } & \text { 間 影 } & \text { カ } & \text { 明 局 純 }\end{array}$ 就 カ 要

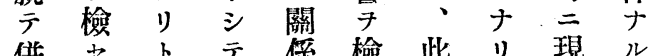

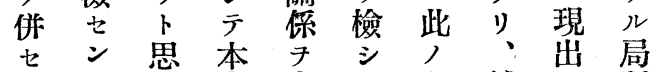
測卜 惟 賽 筧 タ 間 然

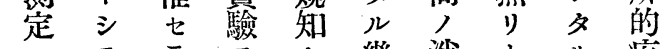

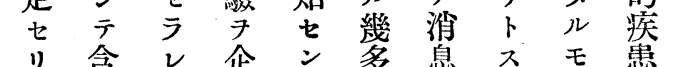

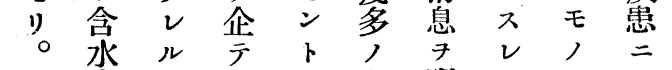
炭力 タシ 業明バトア

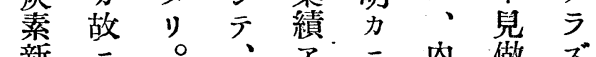
新 、

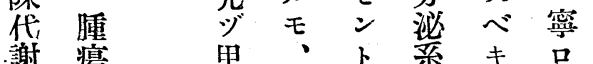

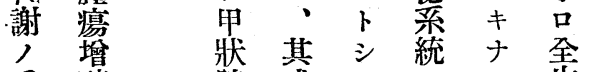
重 殖 腺 威 素

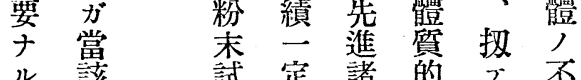

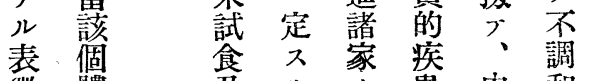

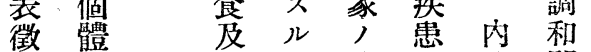
夕人侸至諸多分即

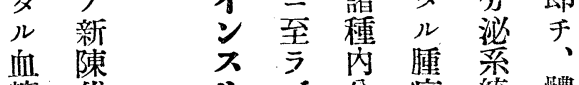

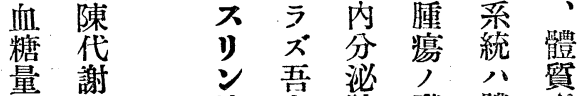

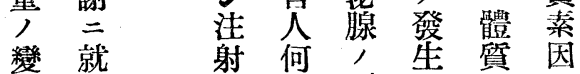

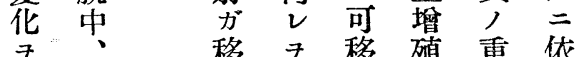
腫含 植探植要り 湢水動 ル性ノナテ 增炭物ヤ董間ル惹

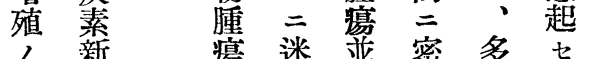

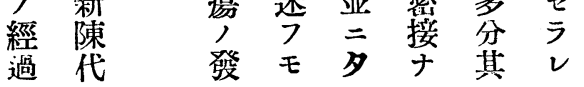



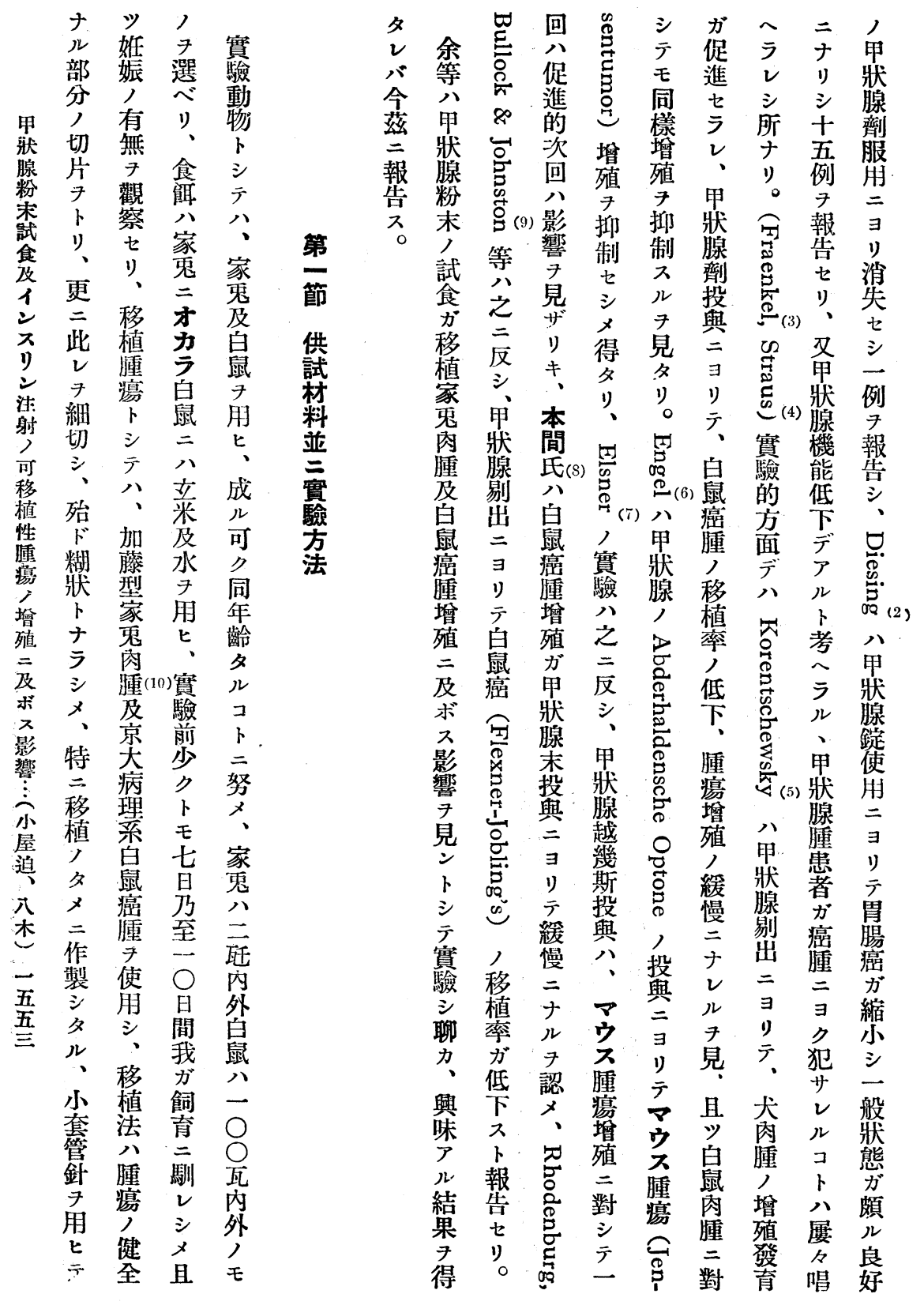


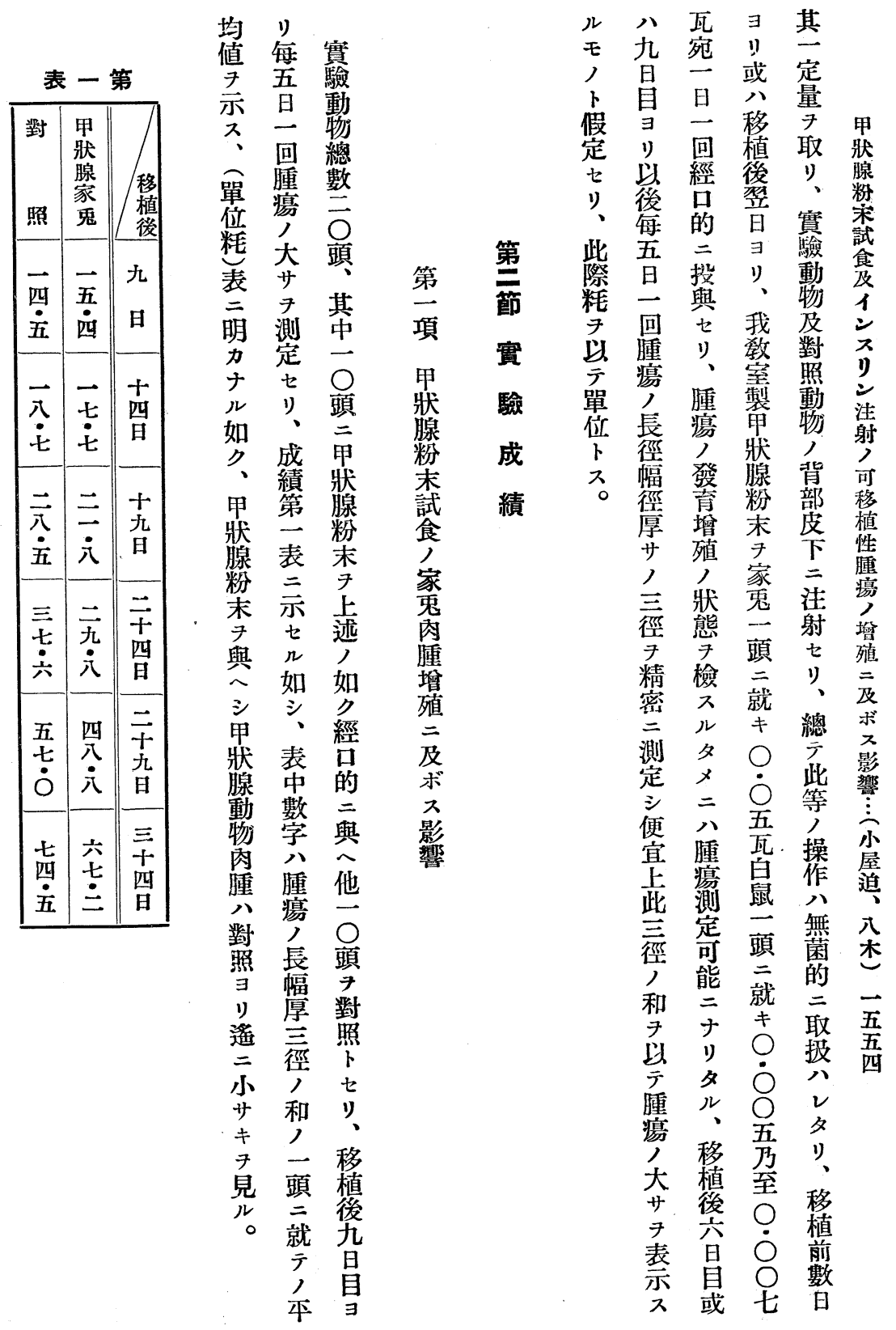




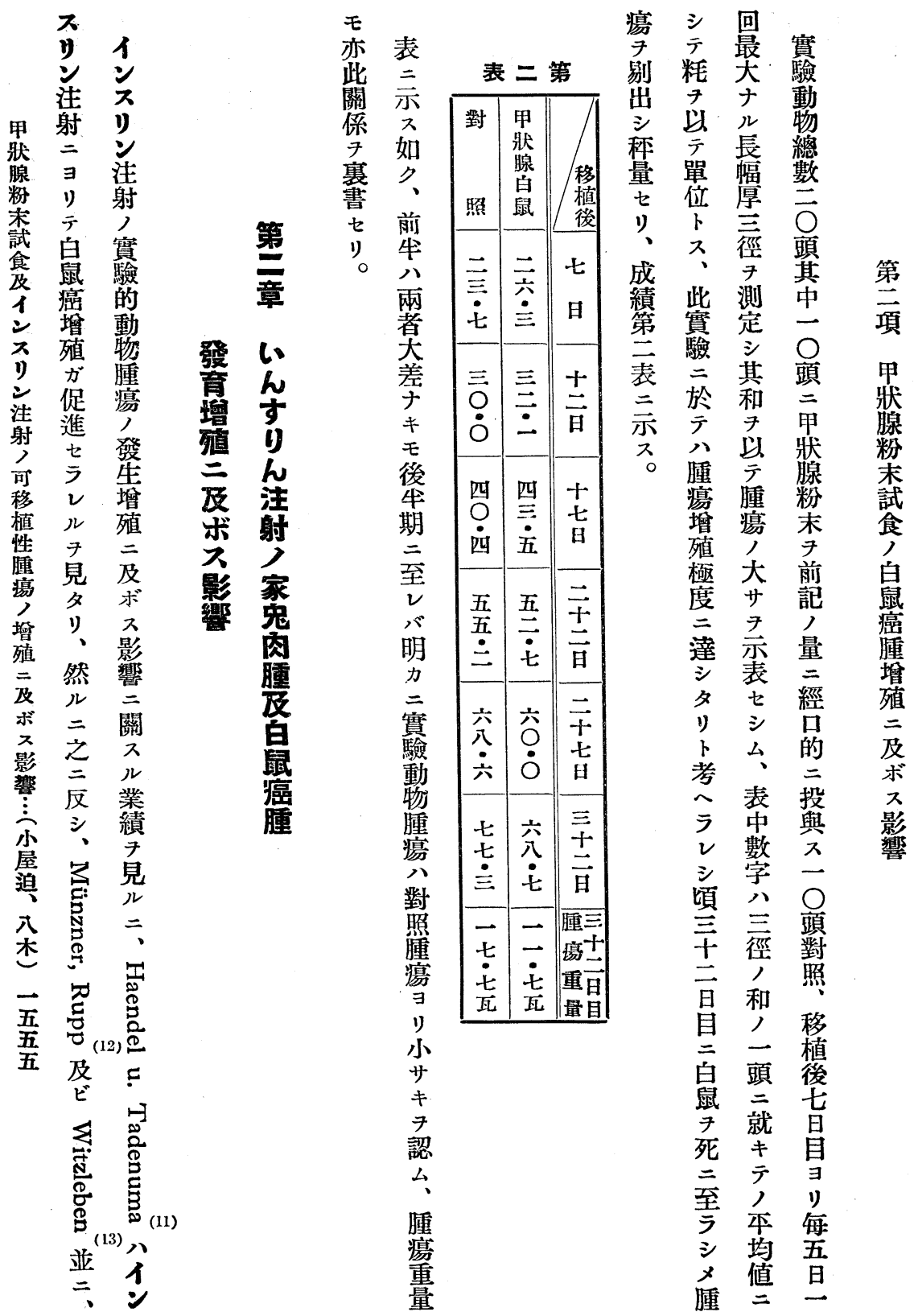




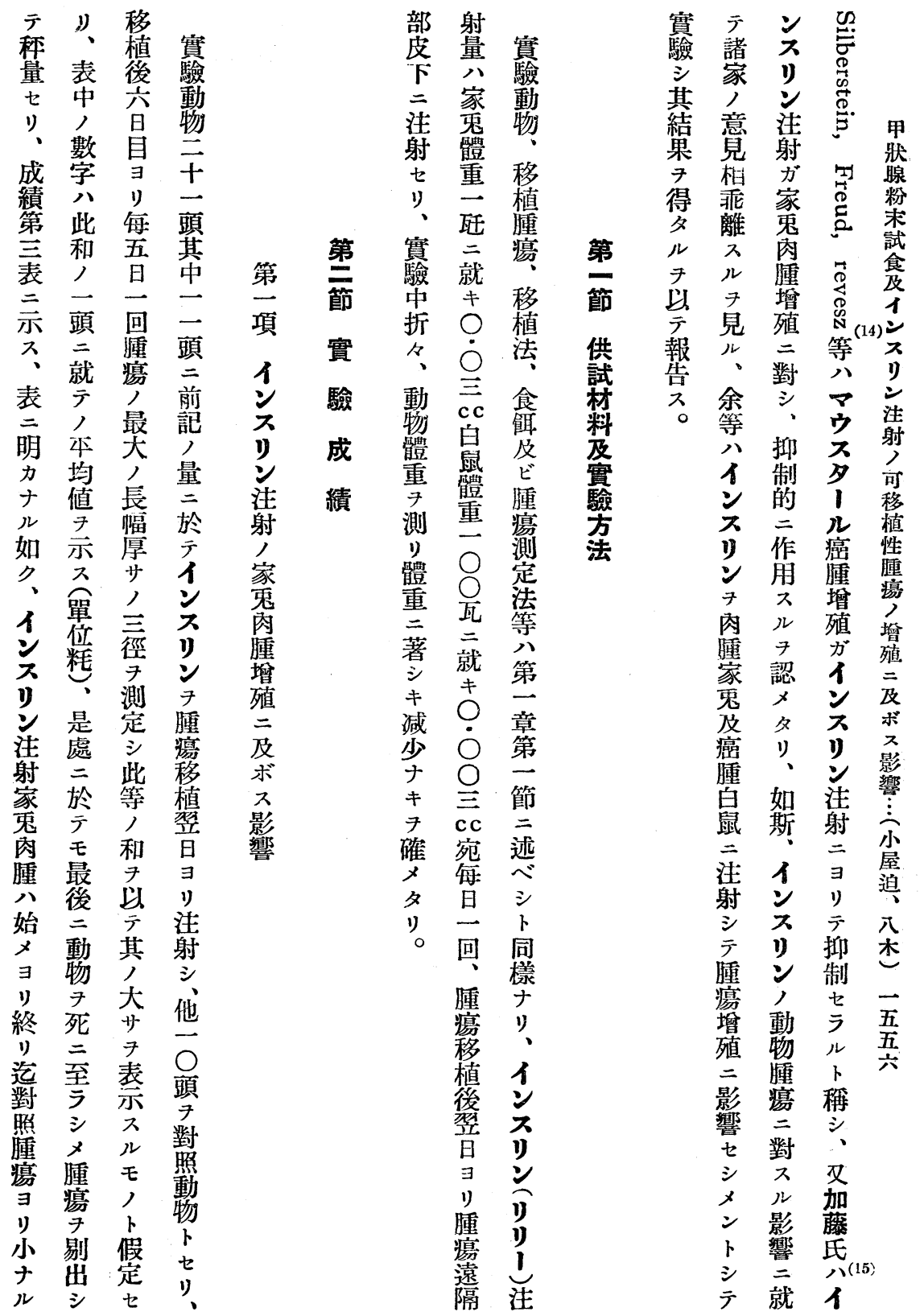




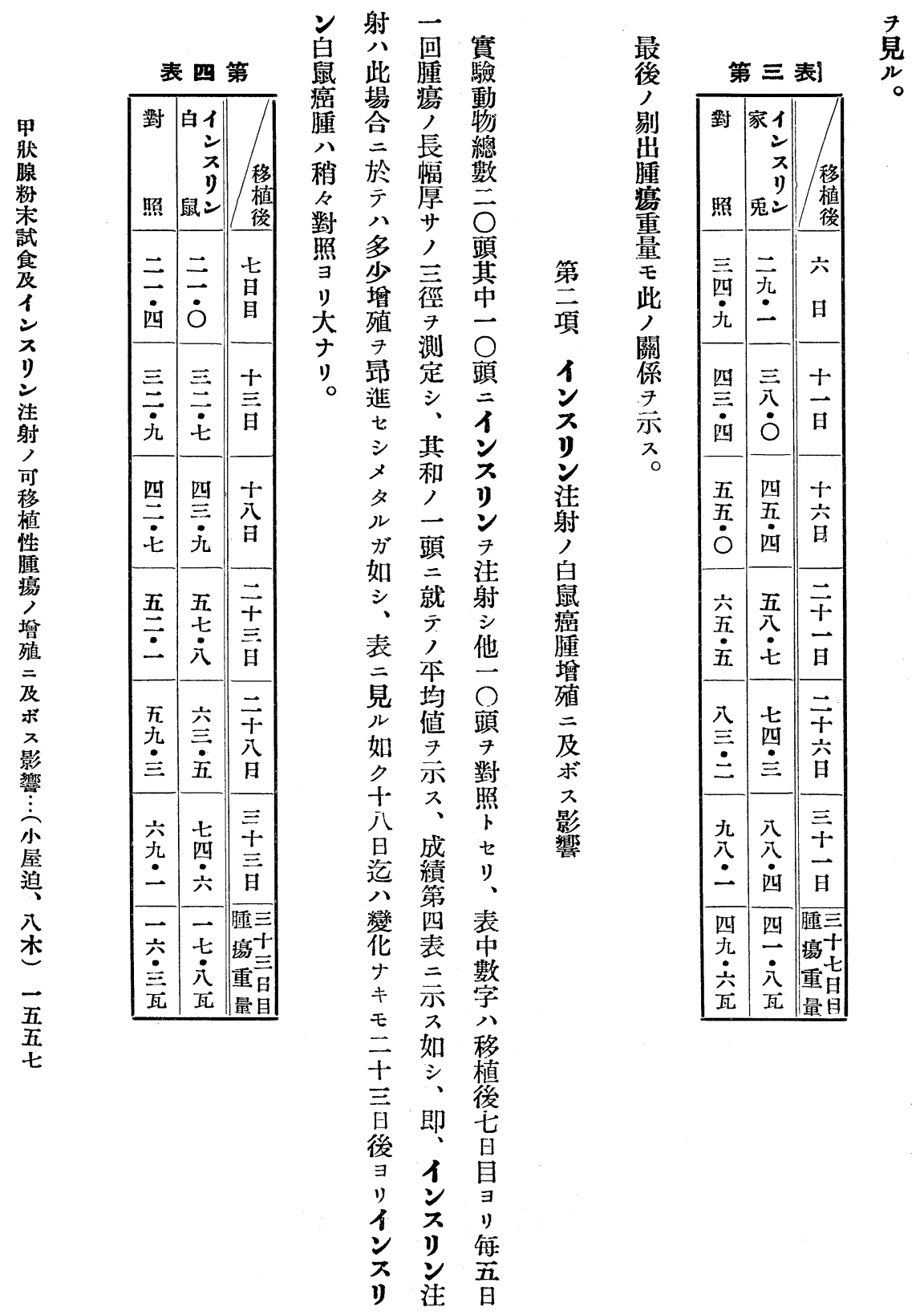




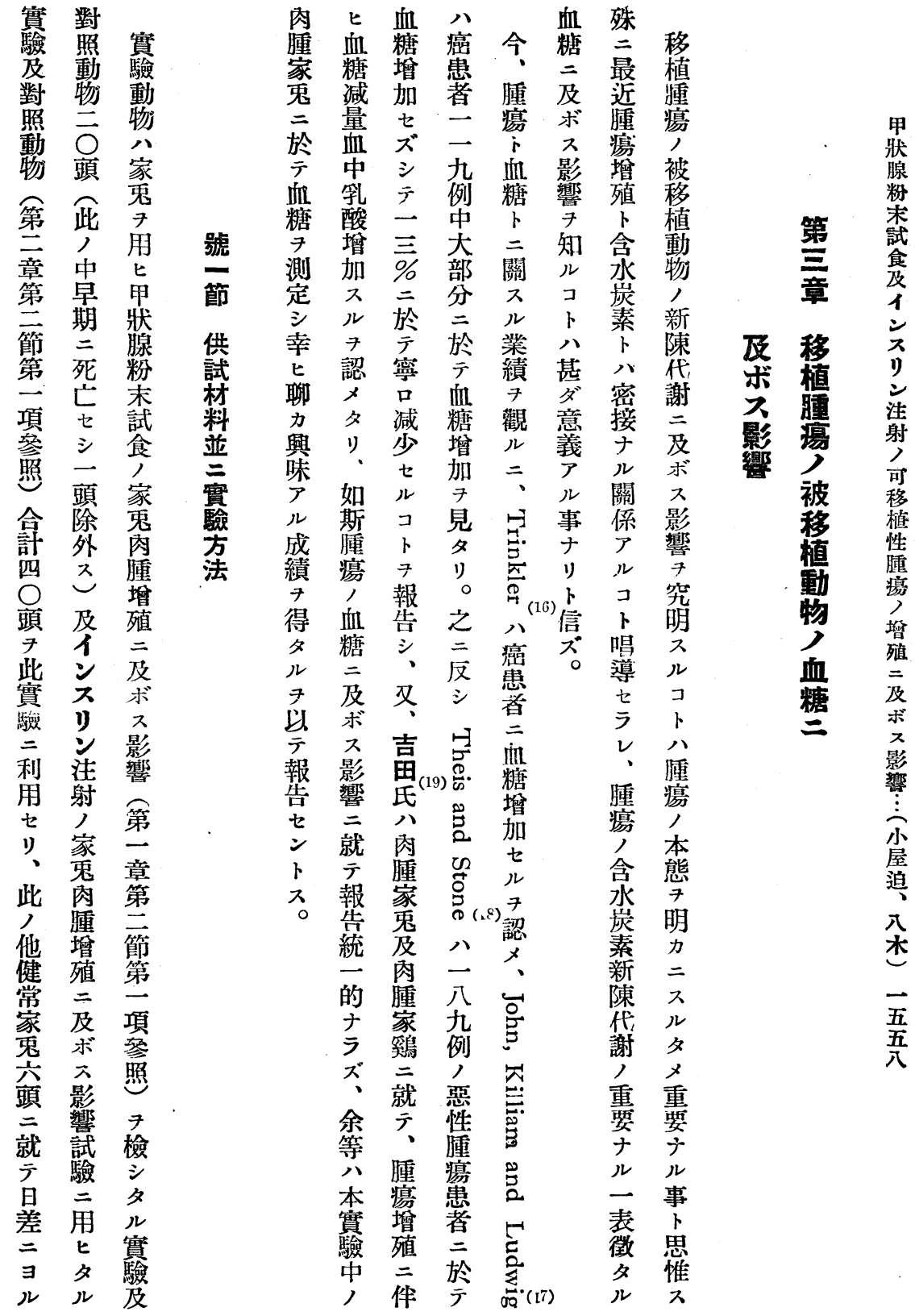




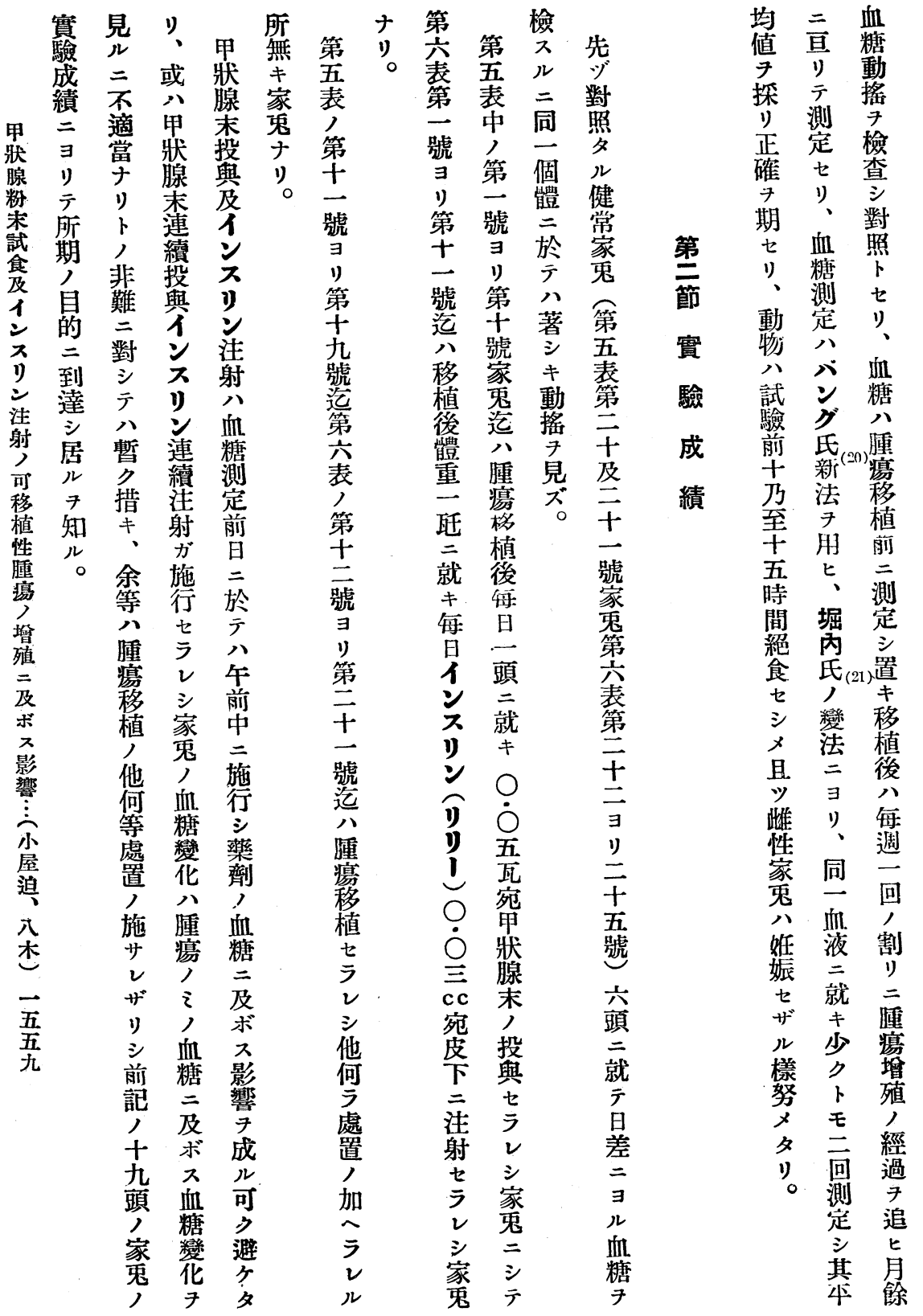




\begin{tabular}{|c|c|c|c|c|c|c|c|c|c|c|}
\hline \multicolumn{9}{|c|}{ 隀 瘍 移 植 動 物 } & \multicolumn{2}{|c|}{ 健常家鬼 } \\
\hline $\mathrm{XI}$ & XII & XIII & XIV & $X V$ & XVI & XVII & $\mathrm{XVIII}$ & $X I X$ & $X X$ & $\mathrm{XXI}$ \\
\hline$\hat{\delta}$ & + & 古 & 今 & + & $\hat{\delta}$ & $\uparrow$ & q & $q$ & $\uparrow$ & ㅇ \\
\hline 2145 & 2080 & 2140 & 1890 & 2060 & 2020 & 2015 & 2065 & 2070 & 2220 & 2130 \\
\hline 0.106 & 0.104 & 0.108 & 0.108 & 0.097 & 0.108 & 0.106 & 0.109 & 0.110 & 0.109 & 0.100 \\
\hline 0.099 & 0.104 & 0.115 & 0.107 & 0.095 & 0.107 & 0.106 & 0.108 & 0.096 & 0.105 & 0.098 \\
\hline 0.096 & 0.102 & 0.103 & 0.097 & 0.100 & 0.110 & 0.108 & 0.108 & 0.108 & 0.107 & 0.104 \\
\hline 0.093 & 0.102 & 0.109 & 0.103 & 0.096 & 0.107 & 0.106 & 0.110 & 0.109 & 0.111 & 0.097 \\
\hline 0.090 & 0.100 & 0.113 & 0.101 & 0.094 & 0.101 & 0.090 & 0.101 & 0.118 & 0.105 & 0.101 \\
\hline 0.068 & 0.091 & 0.108 & - & 0.077 & 0.090 & - & 0.105 & 0.115 & 0.109 & 0.104 \\
\hline
\end{tabular}

\begin{tabular}{|c|c|c|c|c|c|c|c|c|c|c|c|c|}
\hline \multicolumn{3}{|r|}{ 腫 } & \multicolumn{2}{|c|}{ 演 移 植 } & 家 & \multicolumn{3}{|l|}{ 鬼 } & \multicolumn{2}{|c|}{ 侥 常 } & \multicolumn{2}{|c|}{ 家 鬼 } \\
\hline XIII & XIV & $X V$ & XVI & XVII & XVIII & XIX & $X X$ & XXI & XXII & XXIII & XXIV & $X X V$ \\
\hline$\hat{\delta}$ & $q$ & $\hat{\delta}$ & ㅇ & $\hat{\delta}$ & $\hat{\sigma}$ & $\hat{o}$ & q & $\hat{\delta}$ & $\hat{\delta}$ & 운 & 字 & q \\
\hline 2030 & 2250 & 1810 & 2090 & 1950 & 1845 & 2060 & 1970 & 2065 & 2030 & 1945 & 1900 & 2000 \\
\hline 0.114 & 0.101 & 0.106 & 0.105 & 0.102 & 0.097 & 0.099 & 0.109 & 0.095 & 0.099 & 0.105 & $|0.112|$ & 0.090 \\
\hline $0.09 s$ & 0.097 & 0.104 & 0.098 & $|0.099|$ & 0.085 & 0.093 & 0.104 & 0.085 & 0.110 & 0.110 & $0.112 \mid$ & 0.089 \\
\hline 0.111 & 0.111 & 0.097 & 0.108 & $0.097 \mid$ & 0.086 & 0.094 & 0.105 & 0.083 & $0.103 \mid$ & 0.104 & $|0.110|$ & 0.095 \\
\hline 0.091 & 0.107 & 0.104 & 0.096 & 0.095 & 0.075 & 0.091 & 0.101 & 0.081 & 0.099 & 0.106 & 0.106 & 0.091 \\
\hline 0.110 & 0.100 & 0.110 & $0.109 \mid$ & $|0.092|$ & 0.075 & $|0.080|$ & $0.091 \mid$ & 0.081 & $0.095 \mid$ & 0.107 & 0.111 & 0.094 \\
\hline 0.106 & 0.095 & 0.105 & 0.101 & $|0.090|$ & 0.062 & 0.079 & 0.084 & $0.068 \mid$ & 0.096 & 0.106 & $|0.110|$ & 0.093 \\
\hline
\end{tabular}




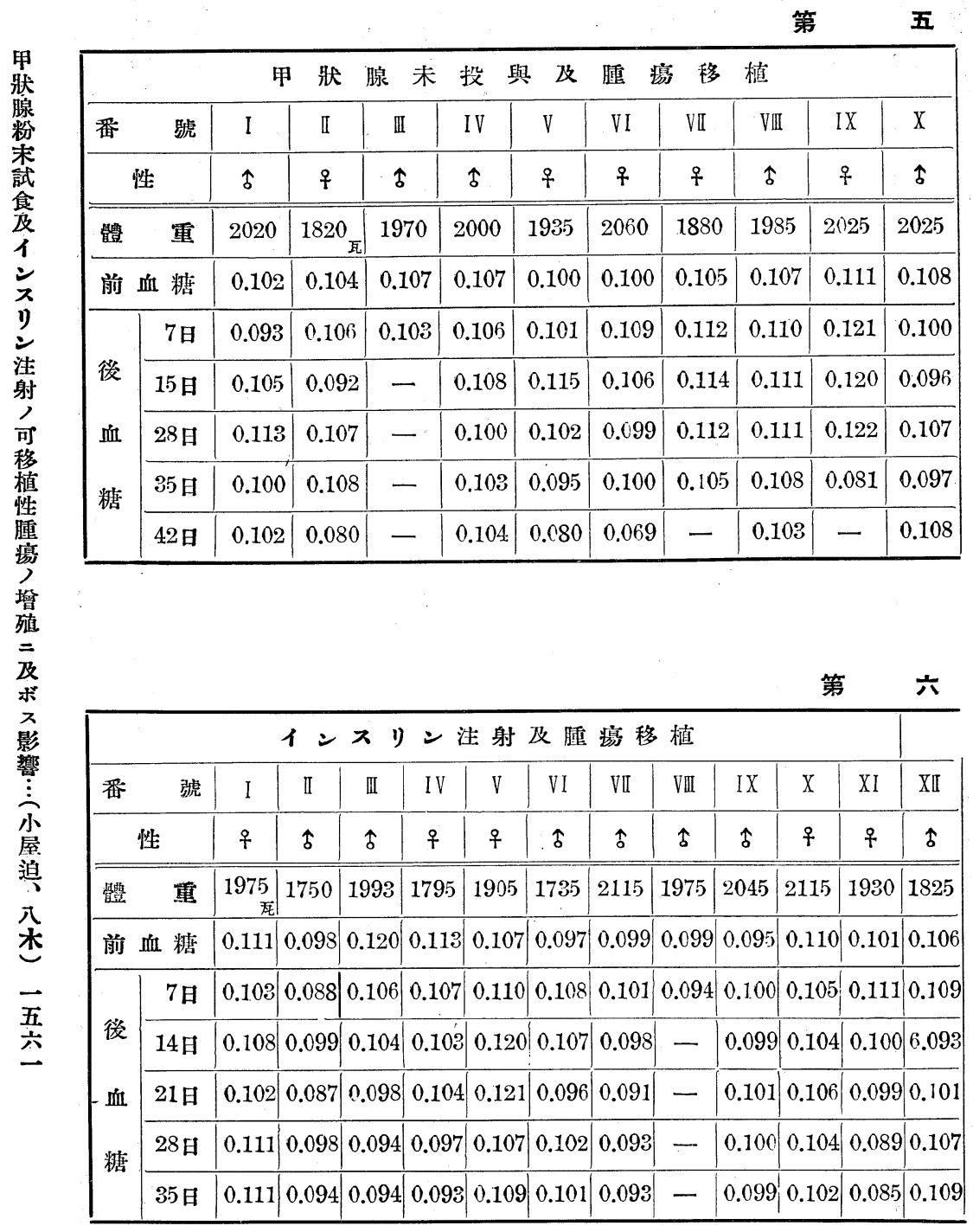




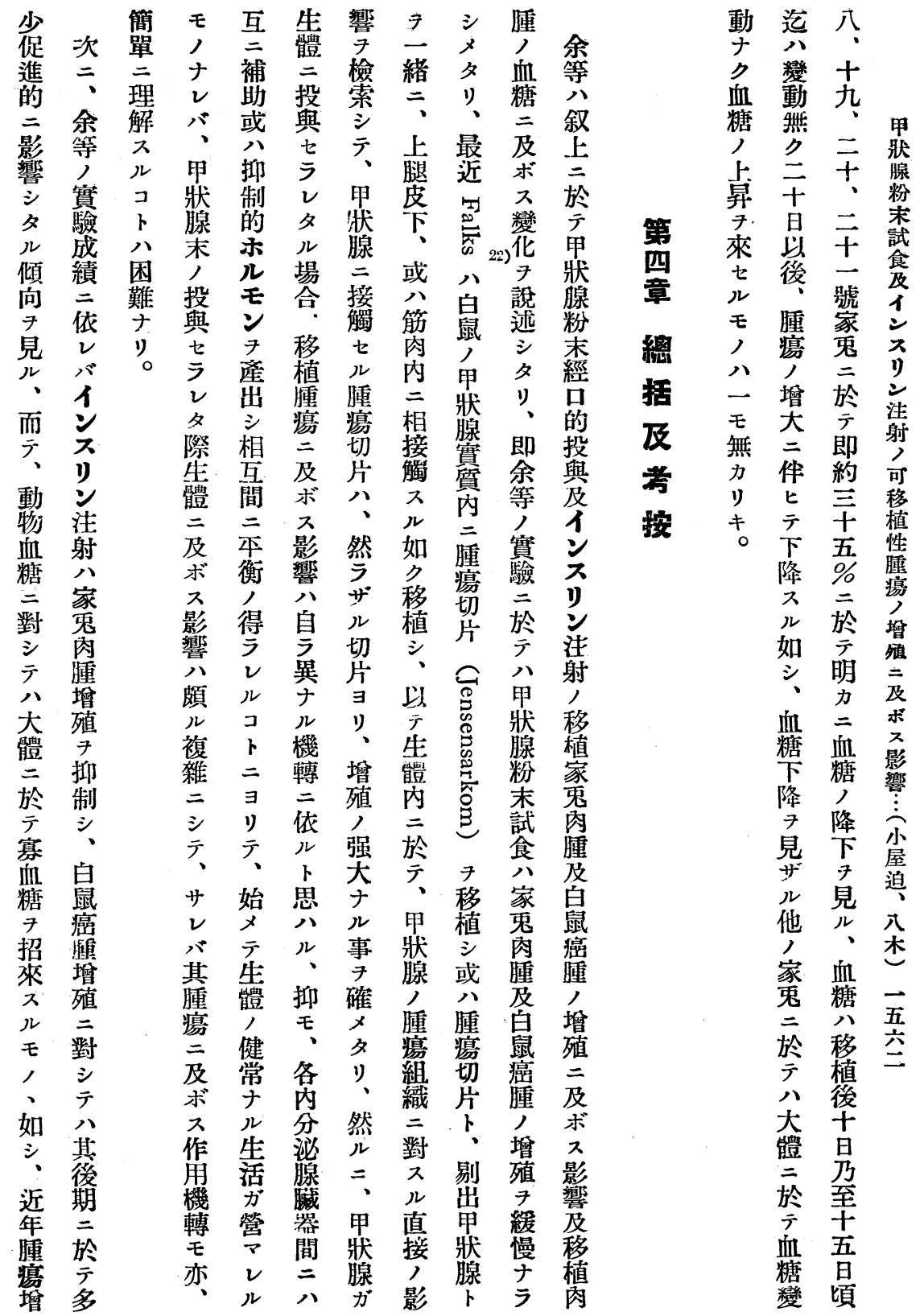




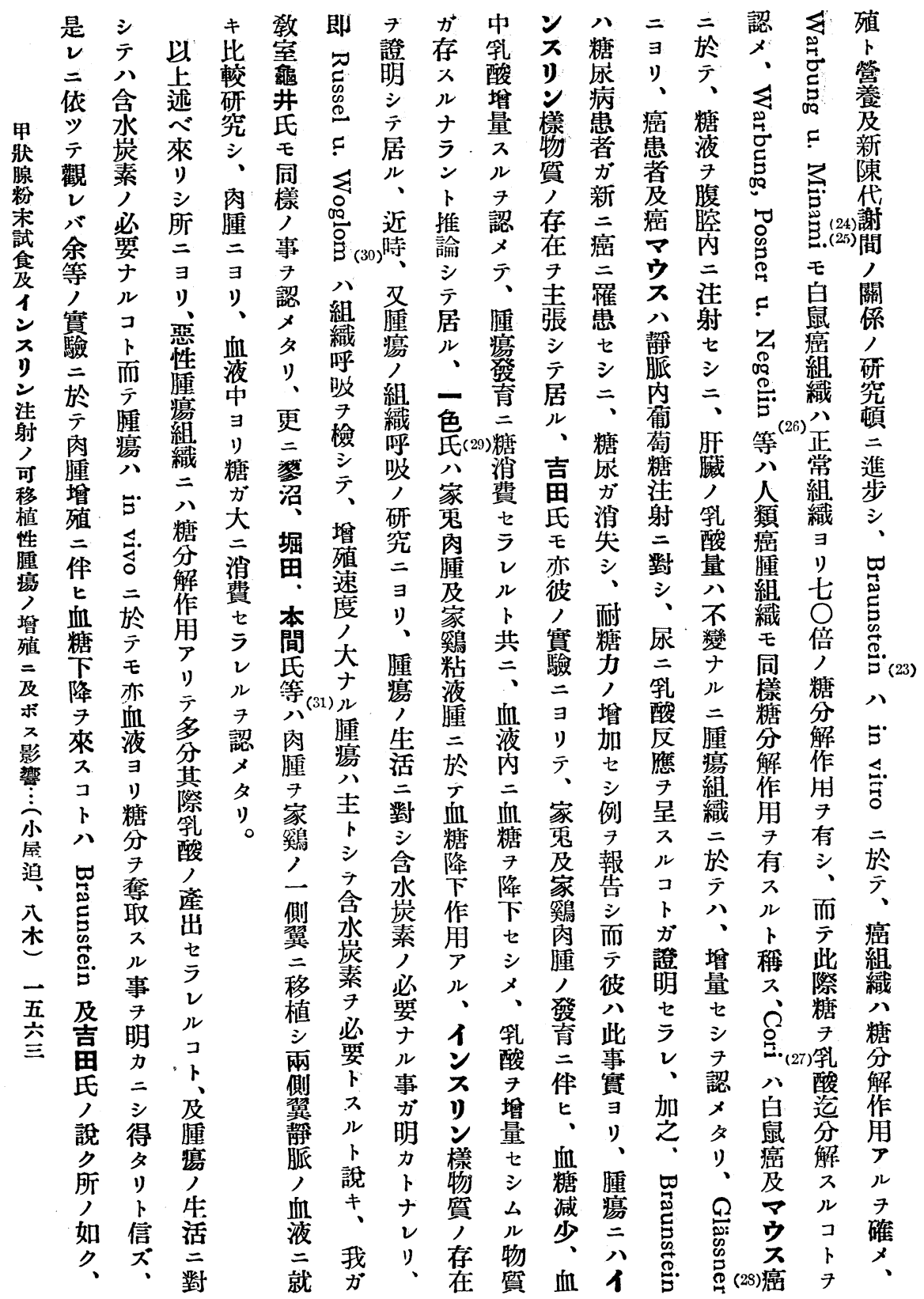




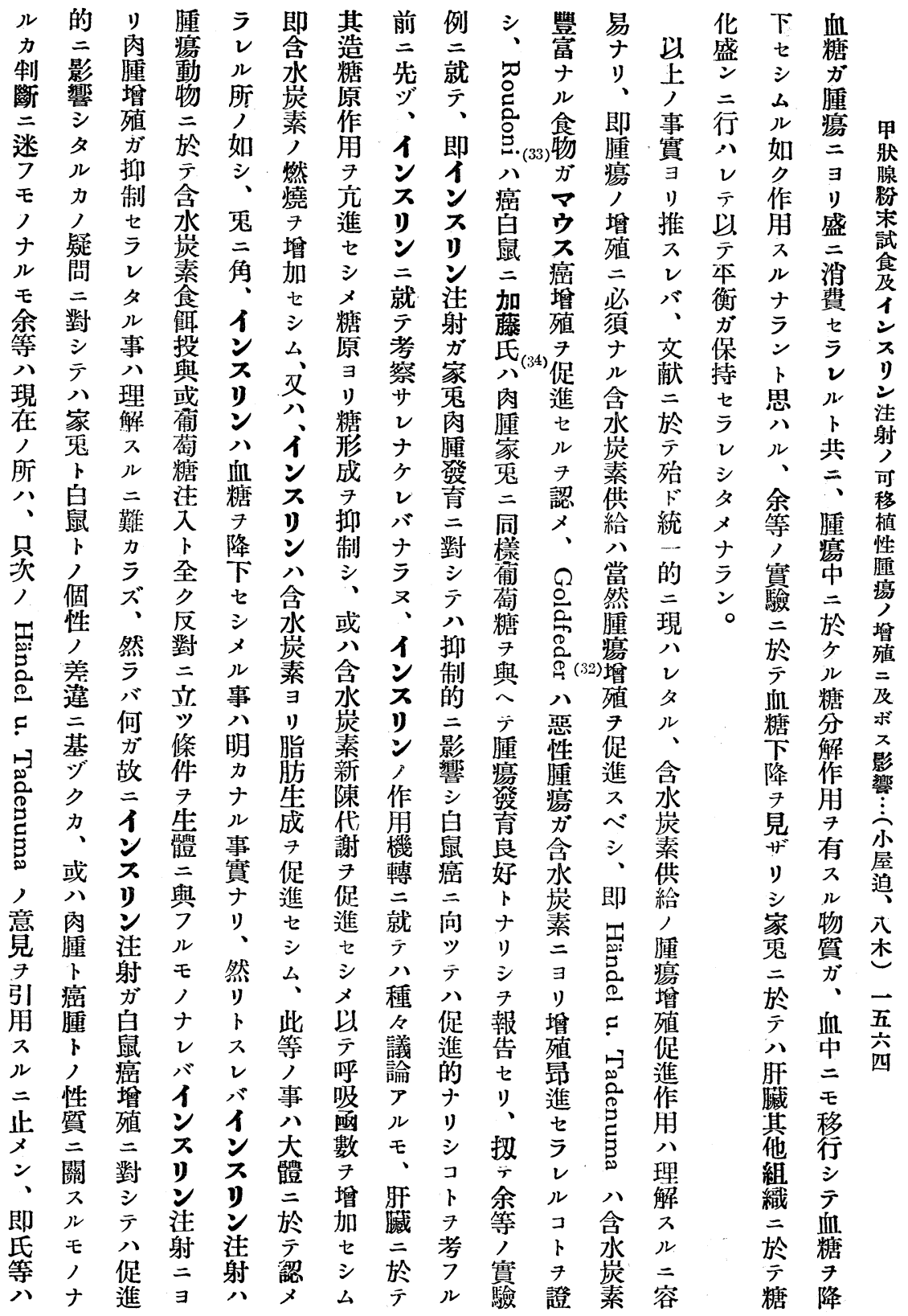




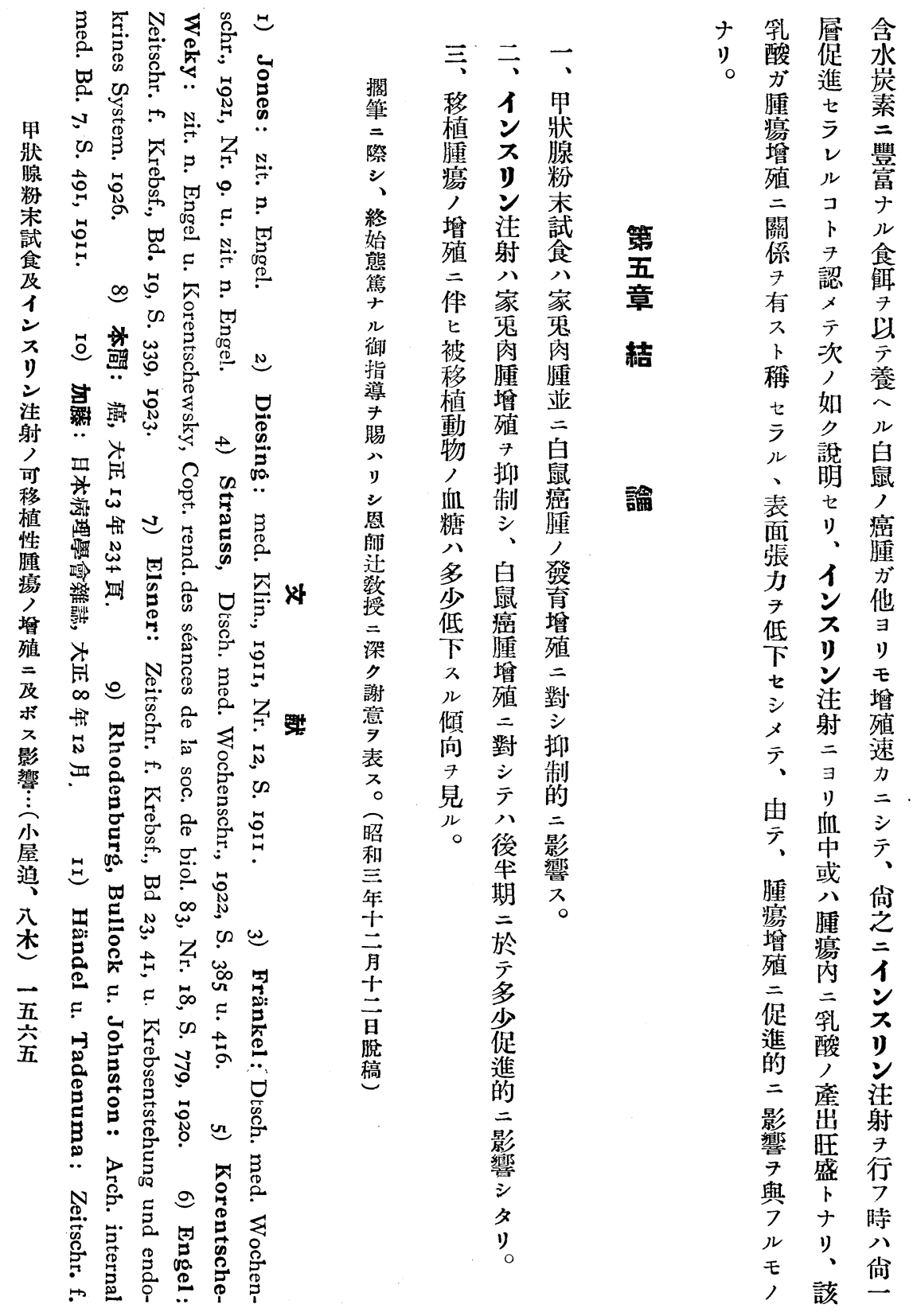




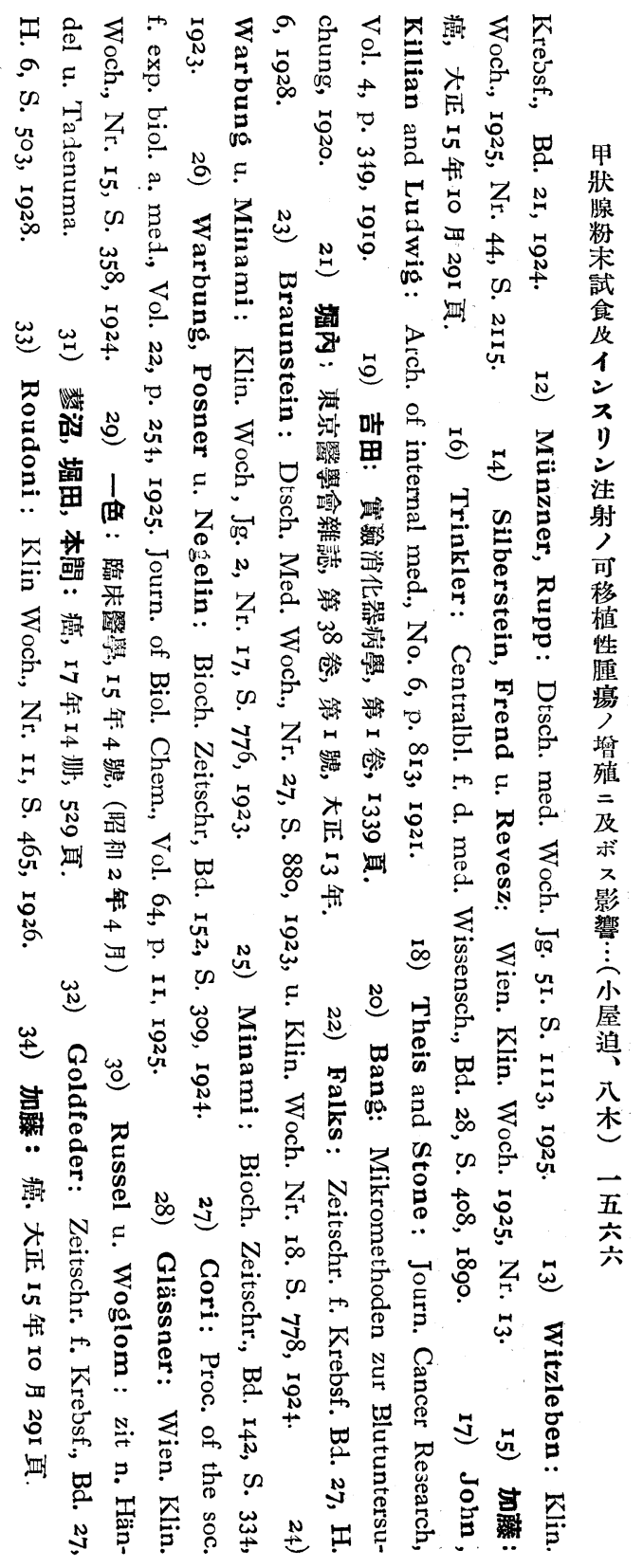




\title{
Ueber den Einfluss der Schilddrüse und des Insulins auf das Wachstum des Impftumors.
}

\author{
Von \\ Dr. T. Koyasako. u. Dr. K. Yagi. \\ (Aus der I. med. Klinik der Kaiserl. Univers. zu Kyoto in Japan. \\ Direktor : Prof. Dr. K. Tsuji.)
}

Die Verfasser studierten an normalen Tieren den Einfluss des Schilddrüsenpräparats und des Insulins auf das Tumorwachstum und an geimpften die Beziehung zwischen dem Tumorwachstum und dem Blutzucker.

Die Resultate waren die folgenden:-

I) Das Schilddrüsenpräparat hemmt das Wachstum des Kaninchensarkoms u. des Rattenkrebses.

2) Das Insulin hernmt das Wachstum des Kaninchensarkoms, aber fördert das Wachstum des Rattenkrebses in geringem Grade.

3) Der Blutzucker des geimpften Tieres neigt nach dem Wachstum des Tumors abzunehmen.

\section{Ueber den Einfluss der Splenektomie und der}

Thyreoidektomie auf den löslichen

Stickstoffgehalt des Blutserums und

verschiedener Organe (Leber,

Niere und Skelettmuskel)

beim Kaninchen. 